\title{
Cyto-adherence of Mycoplasma mycoides subsp. mycoides to bovine lung epithelial cells
}

\author{
Racheal Aye ${ }^{1 *}$, Martin Kiogora Mwirigi ${ }^{1}$, Joachim Frey ${ }^{2}$, Paola Pilo ${ }^{2}$, Joerg Jores ${ }^{1,2}$ and Jan Naessens ${ }^{1}$
}

\begin{abstract}
Background: Mycoplasma mycoides subsp. mycoides ( $\mathrm{Mmm}$ ) is the causative agent of contagious bovine pleuropneumonia (CBPP), a respiratory disease of cattle, whereas the closely related Mycoplasma mycoides subsp. capri $(M m c)$ is a goat pathogen. Cyto-adherence is a crucial step in host colonization by mycoplasmas and subsequent pathogenesis. The aim of this study was to investigate the interactions between $\mathrm{Mmm}$ and mammalian host cells by establishing a cyto-adherence flow cytometric assay and comparing tissue and species specificity of $\mathrm{Mmm}$ and $\mathrm{Mmc}$ strains.

Results: There were little significant differences in the adherence patterns of eight different $\mathrm{Mmm}$ strains to adult bovine lung epithelial cells. However, there was statistically significant variation in binding to different host cells types. Highest binding was observed with lung epithelial cells, intermediate binding with endothelial cells and very low binding with fibroblasts, suggesting the presence of effective adherence of $\mathrm{Mmm}$ on cells lining the airways of the lung, which is the target organ for this pathogen, possibly by high expression of a specific receptor. However, binding to bovine fetal lung epithelial cells was comparably low; suggesting that the lack of severe pulmonary disease seen in many infected young calves can be explained by reduced expression of a specific receptor.

Conclusions: Mmm bound with high efficiency to adult bovine lung cells and less efficiently to calves or goat lung cells. The data show that cyto-adherence of $\mathrm{Mmm}$ is species- and tissue- specific confirming its role in colonization of the target host and subsequent infection and development of CBPP.
\end{abstract}

Keywords: Mycoplasma mycoides subsp. mycoides, Contagious bovine pleuropneumonia, Cyto-adherence, Epithelial cells

\section{Background}

Mycoplasma species (class Mollicutes) are widespread parasites of man, animals, plants and insects that are considered typical surface parasites [1]. Mycoplasma species have a small genome and are the smallest selfreplicating organisms [2]. Owing to their limited biosynthetic capabilities, most Mycoplasma species exhibit strict host and tissue specificities [2]. Due to lack of a cell wall, mycoplasmal adhesins must be part of their cell membrane allowing for direct contact between the mycoplasmal cell membrane and specific receptors on the host cell membrane [3]. This close interaction probably creates a micro-environment which allows for the uptake of important nutrients and accumulation of mycoplasmal metabolic end products causing damage to host

\footnotetext{
* Correspondence: racheal.aye@gmail.com

'International Livestock Research Institute, P. O. Box 30709-00100, Nairobi, Kenya

Full list of author information is available at the end of the article
}

cell membranes [1]. Adhesion mechanisms of M. pneumoniae [4] and M. genitalium [5] are the best studied among Mycoplasma species. In M. genitalium defective mutants of the adhesions P1 and P30 have been shown to be avirulent, hence considering them as major virulence factors, [6]. For $M$. conjunctivae, adhesion was shown to depend on the RGD motif (Arg-Gly-Asp) of Lipoprotein $\mathrm{T}(\mathrm{Lpp} \mathrm{T})$, a protein belonging to the $\alpha$ integrin binding lectin family that includes fibronectin, vibronectin, fibrillin and von Willebrand factor [7]. No adhesion molecules of Mycoplasma mycoides subsp. mycoides $(\mathrm{Mmm})$ have been described yet.

$\mathrm{Mmm}$ is the causative agent of contagious bovine pleuropneumonia (CBPP), a severe, highly contagious respiratory disease of cattle. The disease has also been reported in Italian buffaloes (Bubalus bubalis) [8], American bison (Bison bison) and Asian yak (Bos grunniens), but never in African buffalo (Syncerus caffer) [9]. CBPP is transmitted via aerosols of infected animals and 
is characterized by severe inflammatory, exudative lesions at lung and pleural membranes. In calves however, infection of $\mathrm{Mmm}$ results mainly in swollen painful limbs (arthritis) and associated lameness, but rarely in pulmonary lesions [9]. $\mathrm{Mmm}$ belongs to the closely related M. mycoides cluster [10] which includes four other species and subspecies, namely M. mycoides subsp. capri $(\mathrm{Mmc}), \mathrm{M}$. capricolum subsp. capripneumoniae, $M$. capricolum subsp. capricolum, and M. leachii. Although $M m c$ and $M m m$ are phylogenetically closely related [11], they greatly differ in host tropism [12]. Unlike $\mathrm{Mmm}$, $M m c$ affects small ruminants causing clinical signs including mastitis, arthritis, kerato-conjonctivitis, pneumonia and septicemia, abbreviated as 'MAKePS' [13]. Mmm has been isolated from sheep and goats [14] however there is no indication that it can cause disease in these species. Likewise, $M m c$ has also been isolated from cattle [15], but has not been reported to cause disease in cattle.

A previous study [16] demonstrated the adherence of $M m m$ to embryonic calf nasal epithelial (ECaNEp) cells using realtime PCR assays. Flow cytometric assays have been previously described to measure cyto-adherence of other Mycoplasma species $[17,18]$. The aim of this study was to set up a novel flow cytometry (FCM)-based high throughput adhesion screening for $\mathrm{Mmm}$ and utilize this model for characterization of adhesion among different ruminant cell lines and a panel of $M$. mycoides strains. This approach might reveal an in vitro binding pattern that correlates with disease outcomes observed in young and adult cattle.

\section{Methods}

\section{Cell culture}

Primary epithelial and endothelial cells were cultured from adult bovine tissues including accessory lung lobe epithelial cells (BoLEC) and aorta endothelial cells (BoAEC), bovine fetal lung epithelial cells (BoFLEC) and caprine lung epithelial cells (CaLEC) were cultured from bovine fetuses and goat lungs respectively. Additionally, previously established immortal bovine skin fibroblasts (IBoSF) were used in this study [19].

BoLEC and CaLEC were cultured using the protease digestion technique as described elsewhere [20]. Briefly, tissues were digested using $1 \%$ protease XIV (Sigma, St Louis, USA) at $4^{\circ} \mathrm{C}$ overnight before collecting cells. BoAEC were cultured using the same technique as described above however tissues were digested in $0.25 \%$ collagenase (Sigma, St Louis, USA) [21]. BoFLEC were cultured according to a method described by Schweizer and Peterhans (1999) [22] with slight modifications. Fetal lung tissue was digested in trypsin-EDTA (0.025\%: 0.01\%) in $\mathrm{PBS}$ at $37^{\circ} \mathrm{C}$ for $1 \mathrm{~h}$ with shaking (200 rpm). All cell lines were maintained in Dulbecco's minimum essential medium (DMEM) supplemented with 10\% inactivated fetal bovine serum (Sigma, St Louis, USA), $200 \mathrm{IU} / \mathrm{ml}$ penicillin, $150 \mu \mathrm{g} / \mathrm{ml}$ streptomycin, $1 \mu \mathrm{g} / \mathrm{ml}$ nystatin, $2 \mathrm{mM} \mathrm{L}$-glutamine and 0.15 M 2-mercaptoethanol.

\section{Mycoplasma culture preparations}

$M m m$ and $M m c$ strains used in this study (Table 1) were cultured in $20 \mathrm{ml}$ "pleuropneumonia -like organism" (PPLO) medium (Becton Dickinson, Park, USA) supplemented with $10 \%$ horse serum (Sigma, St Louis, USA), $0.9 \mathrm{~g} / \mathrm{l}$ yeast extract, $0.5 \%$ glucose and $0.03 \%$ penicillin $\mathrm{G}$ at $37^{\circ} \mathrm{C}$ for 48 and $18 \mathrm{~h}$ to a density of $10^{8}$ and $10^{9} \mathrm{cfu} / \mathrm{ml}$ respectively. Each Mycoplasma strain concentration was determined by the Spearman-Karber formula [23] before centrifugation. The mycoplasmas were harvested by centrifugation at $6,000 \times \mathrm{g}$ at $4^{\circ} \mathrm{C}$ for $30 \mathrm{~min}$, washed once in DMEM without supplements and suspended in $10 \mathrm{ml}$ of the same media. Final Mycoplasma titers were calculated using optical density at OD650 and readings plotted on a standard curve based on correspondence between OD650 and Mmm numbers as determined by TaqMan Real Time PCR.

\section{Polyclonal rabbit antibody production}

The production of rabbit polyclonal antibodies was approved by the institutional animal care and use committee (IACUC reference number 2008.14). $\mathrm{Mmm}$ strain Afadé was cultured as described above and the proteins prepared by ultra-sonication, and protein concentration determined by the micro $\mathrm{BCA}$ according to the manufacturer's instructions. One six weeks old rabbit was immunized twice with $1 \mathrm{mg}$ of whole cell lysate at an interval of eight weeks. The rabbit was immunized by giving two immunizations with heat inactivated $\left(60^{\circ} \mathrm{C}\right.$ for $10 \mathrm{~min})$ whole cell lysate $(500 \mu \mathrm{l})$ mixed with the same volume of complete Freund's adjuvant in the first immunization or the same volume of incomplete Freund's adjuvant in the boost. At each immunization half of the antigen-adjuvant mixture was administered intradermally $(500 \mu \mathrm{l})$ and half subcutaneously $(500 \mu \mathrm{l})$. Pre-immunization serum was collected two weeks before initial immunization. Post-immunization serum was collected four weeks after the second immunization, heat inactivated at $56^{\circ} \mathrm{C}$ for $30 \mathrm{~min}$, aliquoted and stored at $-20^{\circ} \mathrm{C}$ until use.

The rabbit serum was validated using dot blot for all the Mycoplasma strains used in this study. Briefly, $2 \mu \mathrm{l}$ of proteins from each Mycoplasma strain was dotted on to nitrocellulose membrane $(0.45 \mu \mathrm{m}$ pore size, Bio-rad), and allowed to dry at room temperature for $30 \mathrm{~min}$. Unspecific binding sites on the blot were blocked in 5\% BSA-PBS for $1 \mathrm{hr}$ at room temperature. The blot was then incubated for $1 \mathrm{hr}$ at room temperature with the rabbit serum diluted at 1:2,500. After 3 washes in PBSTween 20, the blots were incubated for $1 \mathrm{hr}$ at room 
Table 1 Mycoplasma strains used in this study*

\begin{tabular}{|c|c|c|c|c|c|c|c|}
\hline Species & & Strain name & Other name ${ }^{* *}$ & Date of isolation & $\begin{array}{l}\text { Country of } \\
\text { isolation }\end{array}$ & Host & Provider $^{+}$ \\
\hline \multirow{8}{*}{\multicolumn{2}{|c|}{$\begin{array}{l}\text { Mycoplasma mycoides subsp } \\
\text { mycoides (Mmm) }\end{array}$}} & Afade & $\mathrm{DL}$ 06/06 & 1968 & Cameroon & Cattle/lung & FLI \\
\hline & & B237 & DL 04/09 & 1997 & Kenya & & KARI \\
\hline & & B66 & & 2000 & & Cattle & \\
\hline & & T144 & DL 12/06 & 1951 & Tanzania & Cattle/vaccine strain & CIRAD \\
\hline & & V5 & DL 641/08 & 1936 & Australia & & $\mathrm{FLI}$ \\
\hline & & Gladysdale & $008 / 06$ & 1953 & & Cattle & \\
\hline & & Madrid & $636 / 08$ & 1993 & Spain & & \\
\hline & & L2 & $008 / 07$ & 1993 & Italy & Cattle/lung & \\
\hline \multirow{9}{*}{$\begin{array}{l}\text { Mycoplasma mycoides subsp } \\
\text { capri (Mmc) }\end{array}$} & \multirow[t]{2}{*}{ Mmc serovar } & PG3 & R 88 & 1950 & Turkey & Goat/type strain & \\
\hline & & Capri-L & $402 / 97$ & 1975 & France & Goat & \\
\hline & \multirow[t]{7}{*}{ Mmm LC serovar } & $83 / 93$ & $387 / 94$ & 1993 & Spain & & \\
\hline & & $136 / 93$ & $383 / 94$ & 1993 & & & \\
\hline & & $171 / 93$ & $388 / 94$ & 1993 & & & \\
\hline & & $152 / 93$ & $385 / 94$ & 1993 & & & \\
\hline & & My325 & $64 / 97$ & 1986 & Croatia & & \\
\hline & & G1313.94 & $211 / 94$ & 1994 & Germany & Sheep & \\
\hline & & G1255.94 & 209/94 & 1994 & & & \\
\hline
\end{tabular}

*Strain selection was done to include a wide geographical location, varied years of isolation and different virulence.

${ }^{+}$FLI-Friedrich Loeffler Institute; KARI- Kenya Agricultural Research Institute; CIRAD- Centre de coopération internationale en recherche agronomique pour le développement.

**All other names are FLI names.

temperature with anti-rabbit IgG (whole molecule)alkaline phosphatase antibody produced in goat (Sigma) at a dilution of 1:5000. After three washes, blots were developed with 5-bromo-4-chloro-3-indolyl phosphate/ nitro blue tetrazolium (BCIP/NBT, Sigma) in alkaline phosphatase buffer $\left(100 \mathrm{mM} \mathrm{NaCl}, 5 \mathrm{mM} \mathrm{MgCl}_{2}\right.$, $100 \mathrm{mM}$ Tris, $\mathrm{pH}$ 9.5).

\section{Indirect immunofluorescent microscopy}

$1 \times 10^{5}$ BoLEC resuspended in $500 \mu$ l complete DMEM were seeded into a six cell well plate (Corning, New York, USA) containing sterile glass cover slips (Thermo Scientific) and cultured for $2-3$ days at $37^{\circ} \mathrm{C}$ in $5 \% \mathrm{CO}_{2}$. Cover slips were collected and washed three times in DMEM without supplements. $\mathrm{Mmm}$ strain Afadé was cultured as described above and $200 \mu \mathrm{l}$ (approximately $1.5 \times 10^{8}$ mycoplasmas) was added to the cell culture and incubated for two hours. Unbound mycoplasmas were washed off three times using $500 \mu \mathrm{l}$ DMEM without supplements, prewarmed to $37^{\circ} \mathrm{C}$. Cells were fixed in $3 \%$ paraformaldehyde for $15 \mathrm{~min}$ at room temperature. Cyto-adherent mycoplasmas were indirectly stained using anti-Mmm Afadé polyclonal rabbit serum (100 $\mu \mathrm{l}$, 1:100 dilution) for 1 hour on ice, followed by washing thrice with $500 \mu \mathrm{l}$ cold DMEM without supplements and 1 hour incubation with goat anti-rabbit FITC (Sigma, St Louis, USA; $100 \mu \mathrm{l}$, 1:500 dilution). Cover slips were air dried and images acquired using a fluorescent microscope (Axio Imager, Carl Zeiss AG, Gottingen, Germany) at a magnification of 400x. A control experiment was done as described above only that mycoplasmas were omitted and the cells were counter stained with 4', 6 -Diamidino-2-phenylindole (DAPI).

\section{Flow cytometry analysis of cyto-adherence}

Cell lines were cultured in 24 well plates to a density of approximately $1.5 \times 10^{5}$ cells per well. To determine the optimum minimum concentration of mycoplasmas for cyto-adherence, all the Mycoplasma strains used in this study were ten-fold serially diluted. The cyto-adherence assay was performed as described above. Unbound mycoplasmas were washed off thrice with $500 \mu \mathrm{l}$ prewarmed DMEM without supplements. Cells with bound mycoplasmas were detached from the culture plates with $250 \mu \mathrm{l}$ PBS/EDTA buffer and the reaction stopped after $3 \mathrm{~min}$ by adding $500 \mu \mathrm{l}$ prewarmed DMEM without supplements, transferred to $1.5 \mathrm{ml}$ eppendorf tubes and centrifuged at $1,000 \mathrm{~g}$ for $10 \mathrm{~min}$. The supernatant was discarded and the cells transferred to 96 round bottom well plates (Corning, New York, USA). Experiments were performed three times in duplicate. Staining was done as described above (100 $\mu \mathrm{l} /$ well, 1:100 dilution), followed by washing thrice with $200 \mu \mathrm{l}$ of cold DMEM without supplements and centrifugation for 2 minutes at 
1000 g. Cells were incubated with goat anti- rabbit FITC (Sigma, St Louis, USA; $100 \mu \mathrm{l} /$ well, 1:250 dilution) for 1 hour on ice. After the final wash, cells were suspended in $100 \mu \mathrm{l}$ of FACS medium (PBS, 2\% horse serum, $0.2 \%$ sodium azide and $2 \%$ formalin). Cells were analysed by flow cytometry (FACS canto II, Becton Dickinson Co., San Jose, USA) in $5 \mathrm{ml}$ falcon tubes according to the manufacturer's instructions. Three thousand signals were acquired and the results presented as dot plots. To calculate the percentage of positive cells, fluorescence threshold was set such that unstained cells without mycoplasmas would have $0 \%$ fluorescence. This threshold was kept the same for all samples of each experiment and reset for each cell type. Percentage of cells with bound mycoplasmas and mean fluorescence intensity (MFI) were calculated using flow jo software [24]. Statistical analysis of the cells with bound mycoplasmas was done using ANOVA.

\section{Results}

\section{Specificity and kinetics of cyto-adherence}

Rabbit serum directed against whole cell antigens of $M m m$ reacted to both $M m m$ and $M m c$ with similar efficiency (see Additional file 1: Figure S1), which justified its subsequent use for the detection of both Mycoplasma subspecies.

Microscopic analysis of adherent $\mathrm{Mmm}$ to BoLEC showed uneven distribution of $\mathrm{Mmm}$ on the cell surface. The adherent mycoplasmas appeared as aggregated bright fluorescent spots on the surface of the cells (Figure 1). Due to the small size of $M m m$, it was not possible to visualize individual Mycoplasma cells under the conditions used.

$\mathrm{Mmm}$ cyto-adherence kinetics were analyzed using an indirect flow cytometry assay with appropriate controls using unstained lung epithelial cells without adherent mycoplasmas to set the fluorescence cut-off level
(Figure 2). In all subsequent experiments the MFI was used to compare binding of $\mathrm{Mmm}$ to target cells, as this was a more representative parameter of the relative average number of mycoplasmas bound per cell. Saturation of $M m m$ binding to BoLEC and $M m c$ to CaLEC occurred 2 hours post infection (Figure 3A) at approximately $10^{8}$ and $10^{9}$ mycoplasmas per $1.5 \times 10^{5}$ cells (Figure $3 \mathrm{~B}$ and $\mathrm{C}$ ). In all subsequent experiments, mycoplasmas from each strain were used at saturating numbers.

Cell lines from different host tissues were cultured to assess the binding specificity of a panel of eight $\mathrm{Mmm}$ strains (Table 1). Maximum binding of all $M m m$ strains occurred on BoLEC, whereas intermediate binding occurred with BoAEC $(\mathrm{p}=0.006)$ and low binding with BoFLEC $\left(\mathrm{p}=2.12 \times 10^{-10}\right)$ and IBoSF $\left(\mathrm{p}=7.24 \times 10^{-11}\right)$ (Figure 4).

Cyto-adherence of $\mathrm{Mmm}$ and $\mathrm{Mmc}$ to specific host cells was assessed by testing the binding ability of both Mycoplasma species to goat and cattle cells. We demonstrated a statistically significant difference between the cyto-adherence capacities of $\mathrm{Mmm}$ to BoLEC and CaLEC $\left(\mathrm{p}=1.11 \times 10^{-12}\right)$, with $\mathrm{Mmm}$ binding more efficiently to BoLEC than CaLEC (Figure 5). On the other hand, $M m c$ bound more efficiently to CaLEC than BoLEC (Figure 6) however the difference was less apparent than in the case of $\mathrm{Mmm}$ but statistically significant $(\mathrm{p}=0.006)$.

\section{Intraspecies variation of cyto-adherence capacity}

The different strains of $\mathrm{Mmm}$ did not show much variation in the ability to adhere to BoLEC although some small statistical differences of cyto-adherence capacities could be detected for certain strains; in particular with strain Madrid which seemed to have a higher binding capacity compared to the other strains (Figure 5; see Additional file 2: Table S1). Mmc on the other hand

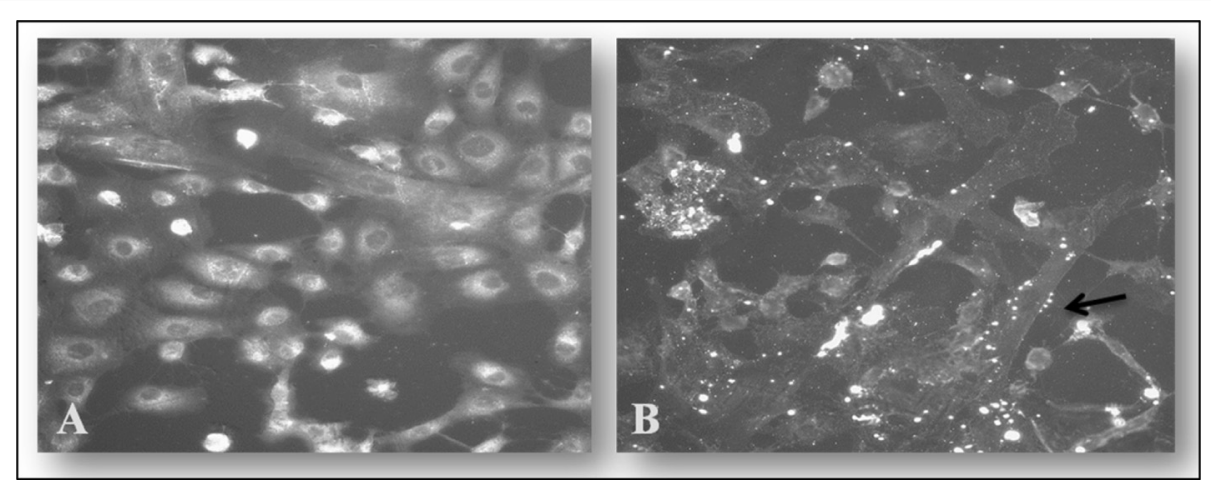

Figure 1 Indirect immunofluorescent staining of Mycoplasma mycoides subsp. mycoides $(\mathrm{Mmm})$ bound to bovine lung epithelial cells (BoLEC). A shows BoLEC without Mmm stained with anti-Mmm (Afade) + anti-rabbit FITC and counter stained with DAPI. B shows BoLEC with adherent Mmm stained with anti-Mmm (Afade) + anti-rabbit FITC and counter stained without DAPI. The arrow indicates bright fluorescent patches of Mycoplasma clusters on the surface of an epithelial cell. 


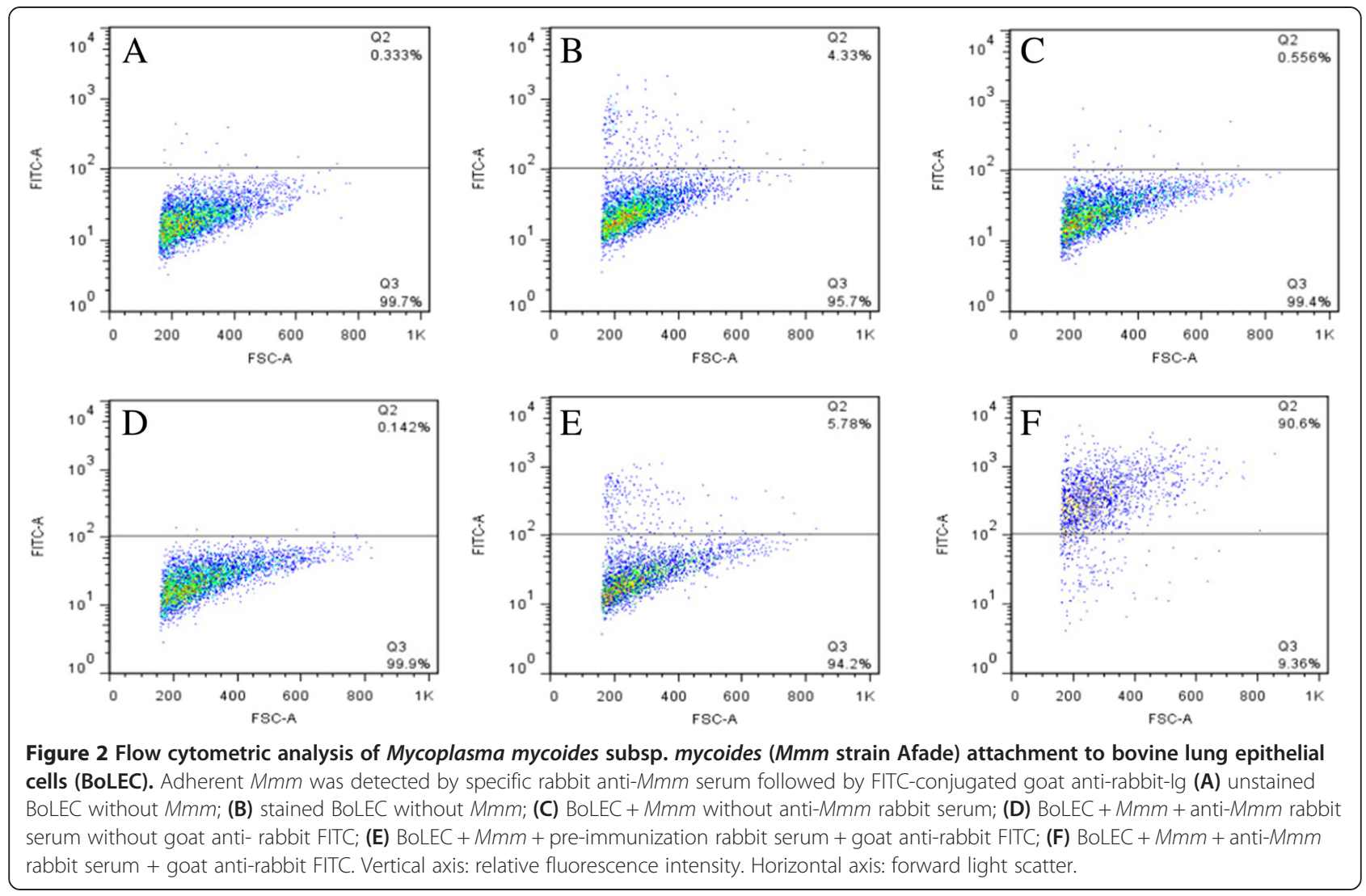

showed relatively high intra-species variation in its capacity to adhere to CaLEC with strains PG3, Capri-L and My325 binding weakly to the cells (Figure 6; see Additional file 3: Table S2).

\section{Discussion}

The aim of this study was to set up a novel flow cytometry (FCM)-based high throughput screening for adhesion of $\mathrm{Mmm}$ and to utilize the model for characterization of adhesion of various strains of $M$. mycoides subsp. mycoides and $M$. mycoides subsp. capri to different ruminant cell lines. In our study, specks of fluorescence could be detected that varied in size, suggesting that $\mathrm{Mmm}$ were often present as clusters or aggregates of different sizes. A previous study also showed a heterogeneous distribution of $M$. bovis on the surface of host cells [20]. Using the flow cytometric assay we determined a statistical difference in the binding of $\mathrm{Mmm}$ to various bovine host tissues; the highest binding was detected with BoLEC, intermediate binding with BoAEC and low binding with IBoSF and BoFLEC. High binding to BoLEC is expected as the main lesions and pathology caused by $M m m$ are found in the lung of adult cattle [25] suggesting that there might be a receptor for $\mathrm{Mmm}$ on lung cells that allows for this interaction. Low adherence of $M m m$ to fetal lung epithelial cells may suggest a lack or low abundance of a receptor for $\mathrm{Mmm}$, which may be acquired through activation of the corresponding genes later in life. This result probably explains why neonatal calves that are infected with $\mathrm{Mmm}$ do not develop severe lung lesions [9]. This also correlates with epidemiological observations showing that CBPP generally affects adult cattle $[9,12]$. In a previous study, binding of $M m m$ to embryonic calf nasal epithelial cells (ECaNEp) was measured in order to analyze the differences in the adhesion capacity of $\mathrm{Mmm}$ strains with diverse degrees of virulence, as ECaNEp cells were used as a model for cytotoxicity. However, this study did not compare host cells of animals of various ages and hence measurements have been done at a relatively low range of binding capacity [16].

Moderate binding to endothelial cells might correlate with pathology seen in capillaries and lymph vessels. $\mathrm{Mmm}$ has been isolated from the lymph nodes of cattle with CBPP [25] and vasculitis is a common occurrence in heavily infected animals. An interaction between mycoplasmas and endothelial cells may contribute to the vasculitis. Subcutaneous inoculation of mycoplasma often causes serious necrotic edema, but not in lymphatic-poor areas, such as nose or tail tip [26] however this method of inoculation does not result in typical clinical CBPP. 

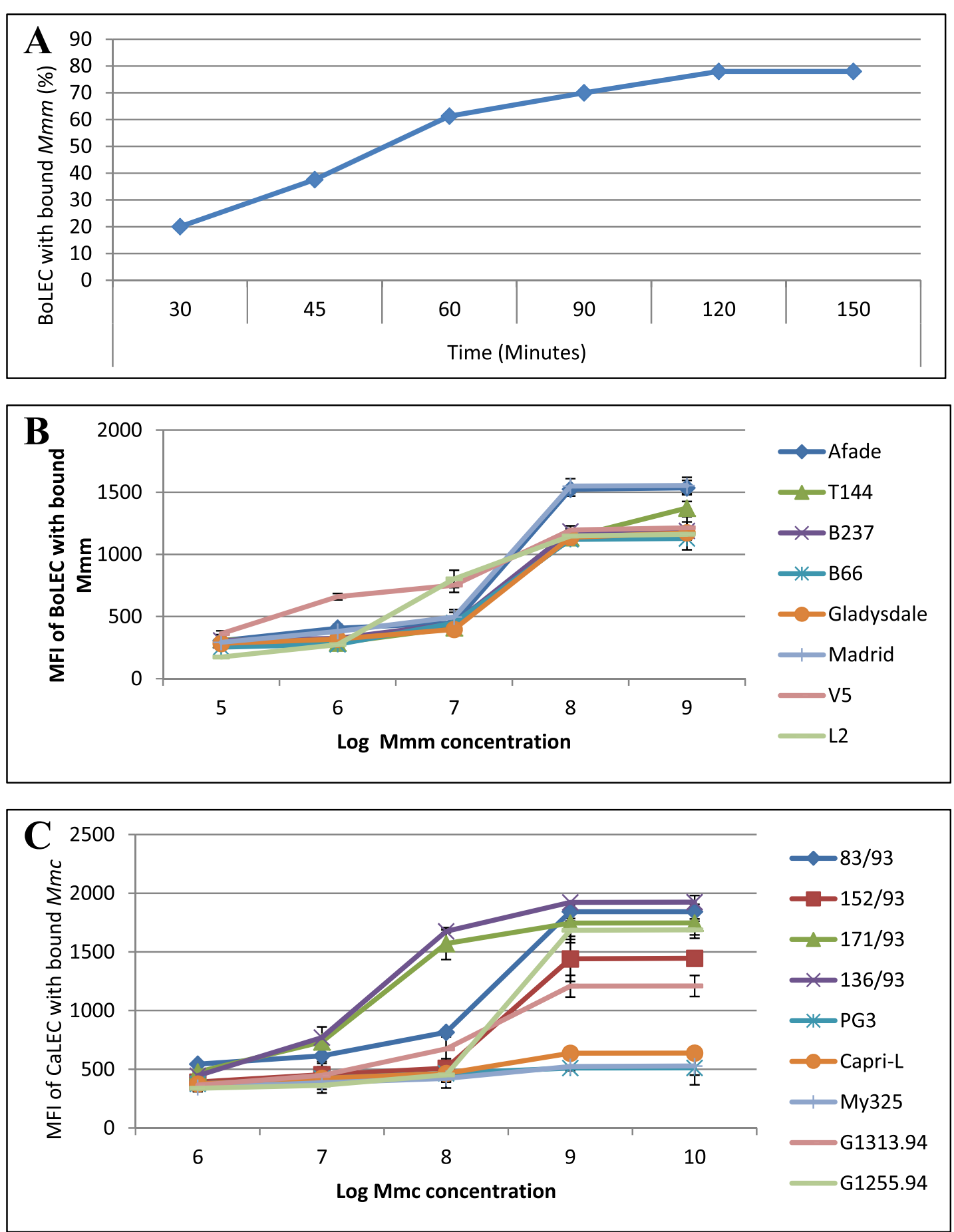

Figure 3 Cyto-adhesion kinetics of Mycoplasma strains used in this study. (A) Adherence of Mycoplasma mycoides subsp. mycoides (Mmm) strain Afade to cattle lung epithelial cells (BoLEC) as a function of incubation time. (B) Serial dilution (1:10) of $\mathrm{Mmm}$ strains and adherence to BoLEC. (C) Serial dilution (1:10) of Mycoplasma mycoides subsp. capri (Mmc) strains and adherence to caprine lung epithelial cells (CaLEC).

According to our results, there was little significant statistical difference between the adherence capacities of the different $\mathrm{Mmm}$ strains tested, which suggests that all strains used expressed the relevant adhesion ligands and the differences in the virulence among these strains is not due to variation in their adhesins. This is also probably due to the fact the $M m m$ strains exhibit very little genetic diversity [11]. The caprine Mycoplasma (Mmc) on the other hand showed more variation in cytoadherence patterns among strains, which could correlate 


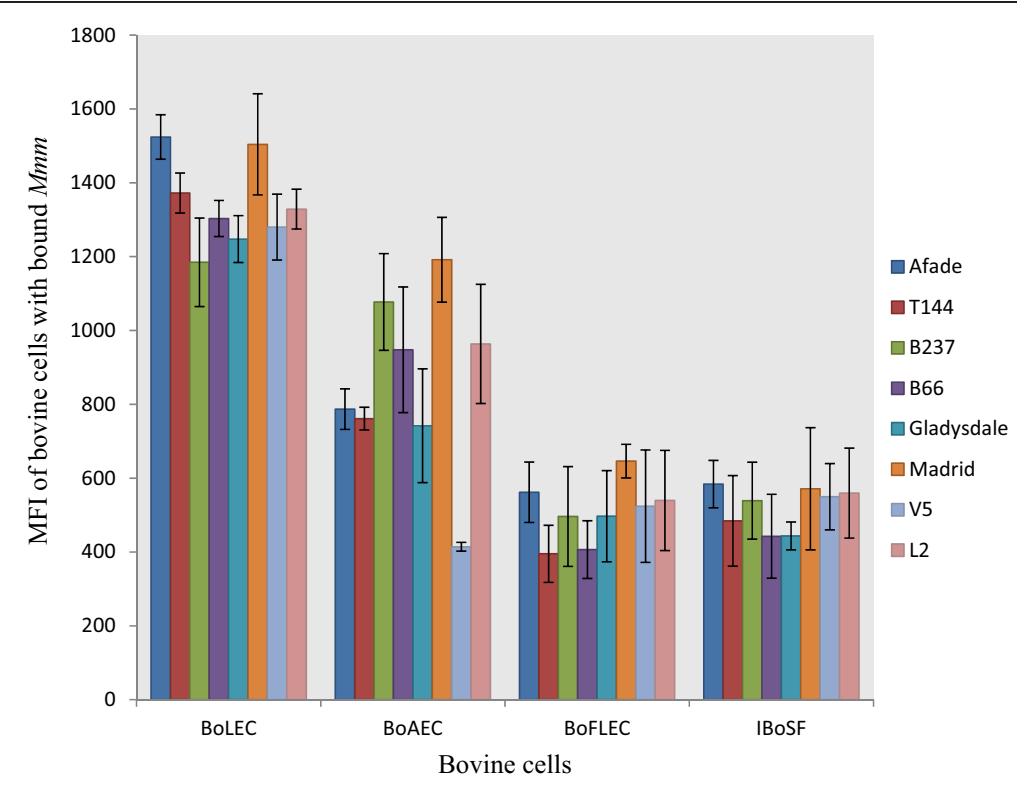

Figure 4 Cyto-adherence capacity of different Mycoplasma mycoides subsp. mycoides $(\mathrm{Mmm})$ strains to different cattle cell lines, expressed as mean fluorescence intensity (MFI) of cells with bound Mycoplasma.

with their broader genetic diversity [11]. But the clinical signs of $M m c$ are not confined to lung, as there are many other manifestations, abbreviated as 'MAKePS' [13]. Adherence to other cell types might show different patterns and assessing the correlations between cytoadherence of $M m c$ strains and different cell types needs further investigation. Furthermore, there is a possibility that the rabbit anti-Mmm serum used in this study might have reacted differently with individual $M m c$ strains. Mmm cyto-adherence assays revealed relevant host species specificity: $\mathrm{Mmm}$ adheres to bovine lung epithelial cells, but very little to caprine lung epithelial

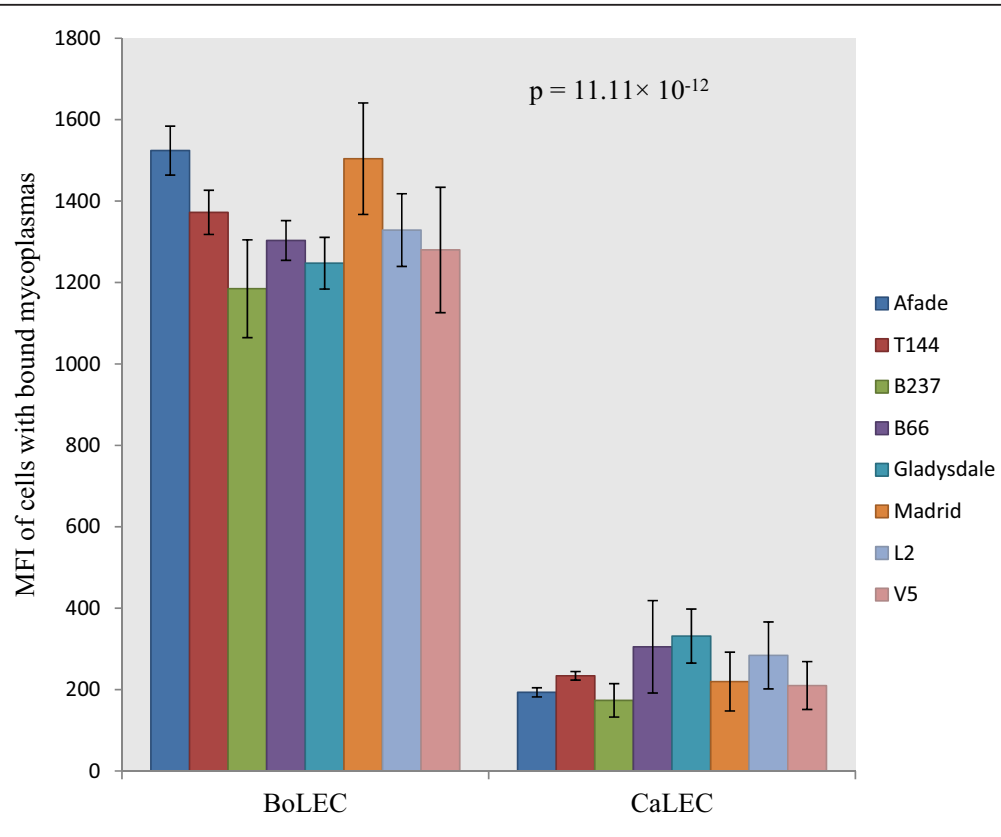

Different host cells.

Figure 5 Cyto-adherence capacity of different Mycoplasma mycoides subsp. mycoides $(\mathrm{Mmm})$ strains to lung epithelial cells from cattle (BoLEC) and goats (CaLEC), expressed as mean fluorescence intensity (MFI) of cells with bound Mycoplasma. 


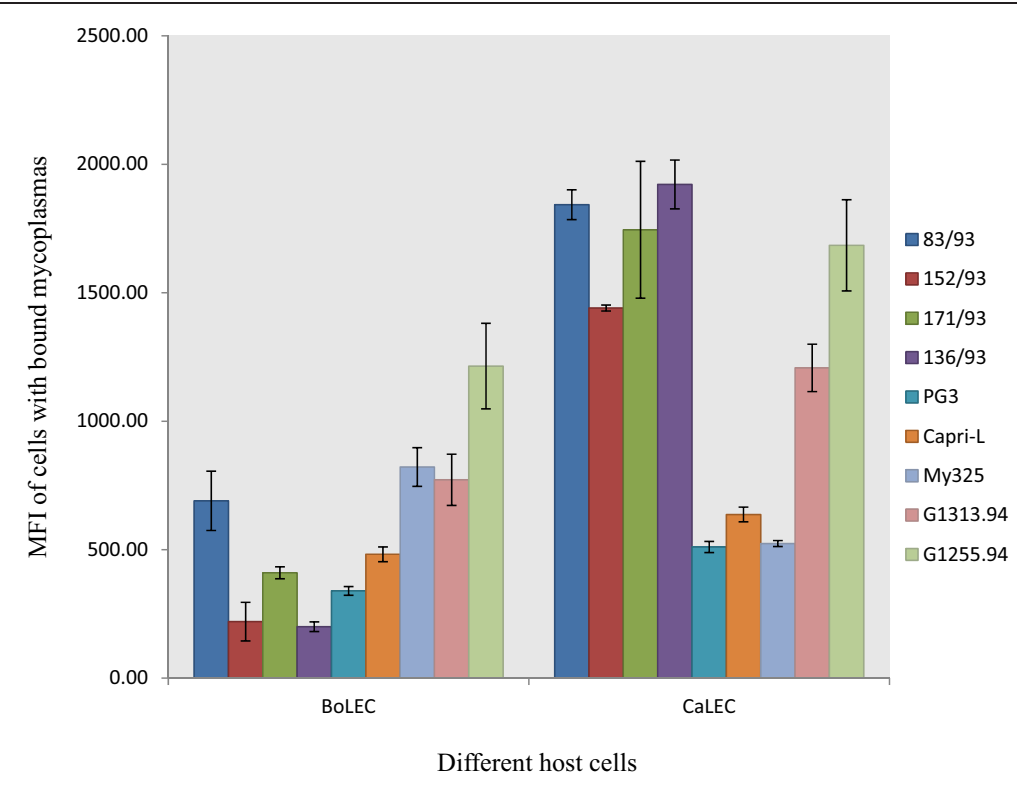

Figure 6 Cyto-adherence of different Mycoplasma mycoides subsp. capri (Mmc) strains to lung epithelial cells from cattle (BoLEC) and goats (CaLEC), expressed as mean fluorescence intensity (MFI) of cells with bound Mycoplasma.

cells. This suggests a correlation between the capacity to adhere to target cells, in this case to cattle cells, and the development of disease specifically in cattle, suggesting the presence of host specific adhesion factors. However, $M m c$ binds to lung cells from both species. This needs further investigation since $M m c$ has never been reported as causing disease in cattle [15] but other factors may influence the disease outcome. The cyto-adherence of $\mathrm{Mmm}$ supports previous reports from other Mycoplasma species that adherence is tissue and organ specific; however it is not uncommon to isolate mycoplasmas from tissues or hosts other than their natural habitats [27].

\section{Conclusion}

Cyto-adherence of $\mathrm{Mmm}$ to mammalian host cells was studied using an indirect, flow cytometric assay. The data show that strong binding of $\mathrm{Mmm}$ is specific to lung epithelial cells from adult cattle, but not fetuses. This correlates with the severe in vivo clinical signs observed in lung tissue of infected, adult cattle, but which are mostly absent in infected, very young calves. An intermediate binding to endothelial cells correlates with pathological signs detected in capillaries and lymph vessels. Binding was weak to other tissue cells and to lung cells from goats, suggesting that a strong binding of $M m m$ with their target cells might be the basis of the species and tissue specificity of CBPP, and be a requisite step in the development of the disease. Blocking adhesion in vivo might represent a valuable target to prevent colonization of the lung by $\mathrm{Mmm}$.

\section{Additional files}

Additional file 1: Figure S1. Dot blot analysis of the ability of rabbit serum to recognize all the strains used in this study. 1. Blank control. No. 2-9. Mycoplasma mycoides subsp. mycoides strains including Afade, T144, B237, B66, Gladysdale, Madrid, V5 and L2 respectively. Numbers 10-18 are Mycoplasma mycoides subsp. capri strains including 83/83, 152/93, 171/93, 136/93, PG3, Capri-L, My325, G1313.94 and G1255.94 respectively. Membrane stained with $\mathrm{Mmm}$ specific rabbit serum raised against strain Afade (1:2500) and goat anti-rabbit alkaline phosphatase conjugated (1:500) (Sigma) and visualized by 5-bromo-4-chloro-3-indolyl phosphate/nitro blue tetrazolium (BCIP/NBT, Sigma).

Additional file 2: Table S1. Statistical analysis of cyto-adherence capacity of Mycoplasma mycoides subsp. mycoides (Mmm) strains to bovine lung epithelial cells (BoLEC).

Additional file 3: Table S2. Statistical analysis of Mycoplasma mycoides subsp. capri $(\mathrm{Mmc})$ strains cyto-adherence to goat lung epithelial cells (CaLEC).

\section{Abbreviations}

BOAEC: Bovine aortic endothelial cells; BoFLEC: Bovine fetal lung epithelial cells; BoLEC: Bovine (adult) lung epithelial cells; CaLEC: Caprine lung epithelial cells; CBPP: Contagious bovine pleuropneumonia; IBoSF: Immortalized (bovine) skin fibroblast; Mmm: Mycoplasma mycoides subsp. mycoides; Mmc: Mycoplasma mycoides subsp. capri; DMEM: Dulbecco's minimum essential medium; DAPI: 4', 6-Diamidino-2- phenylindole; ECaNEp: Embryonic calf nasal epithelial cells.

\section{Competing interests}

The authors declare that they have no competing interests.

\section{Authors' contributions}

AR established the primary cell lines, performed the adhesion assays, performed statistical analysis and drafted the manuscript. MM helped with binding assay and flow cytometric analysis. JJ produces the polyclonal rabbit antibody. JN, JJ and AR designed the study and did analysis of results; JF and PP provided guidance in the adhesion assay and helped with interpretation of data. All authors helped to draft the manuscript and approved the final interpretation of data. 


\section{Acknowledgements}

The project was financed by German Federal Ministry for Economic Cooperation and (Contract No. 81121408, Project No. 09.7860.1-001.00) and the CGAR research program on Livestock and Fish. Racheal Aye was also supported by a grant from the German Academic Exchange Service (DAAD), in-region scholarship.

\section{Author details}

${ }^{1}$ International Livestock Research Institute, P. O. Box 30709-00100, Nairobi, Kenya. ${ }^{2}$ Institute of Veterinary Bacteriology, University of Bern, Bern, Switzerland.

Received: 15 July 2014 Accepted: 30 January 2015

Published online: 07 February 2015

\section{References}

1. Razin S. Adherence of pathogenic mycoplasmas to host cells. BiosciRep. 1999;19(5):367-72.

2. Pilo P, Frey J, Vilei EM. Molecular mechanisms of pathogenicity of Mycoplasma mycoides subsp. mycoides SC. Vet J. 2007;174(3):513-21.

3. Baseman JB, Tully JG. Mycoplasmas: sophisticated, reemerging, and burdened by their notoriety. Emerg Infect Dis. 1997;3(1):21-32.

4. Chourasia BK, Chaudhry R, Malhotra P. Delineation of immunodominant and cytadherence segment(s) of Mycoplasma pneumoniae P1 gene. BMC Microbiol. 2014;14:108.

5. Zeng Y, Liu L, He J, Liu Y, Zhu C, You X, et al. Screening and identification of the mimic epitope of the adhesion protein of Mycoplasma genitalium. Can J Microbiol. 2012;58(7):898-908.

6. Burgos R, Pich OQ, Ferrer-Navarro M, Baseman JB, Querol E, Piñol J. Mycoplasma genitalium P140 and P110 cytadhesins are reciprocally stabilized and required for cell adhesion and terminal-organelle development. J Bacteriol. 2006;188(24):8627-37.

7. Zimmermann L, Peterhans E, Frey J. RGD Motif of lipoprotein T, involved in adhesion of Mycoplasma conjunctivae to lamb synovial tissue cells. J Bacteriol. 2010;192:3773-9.

8. Santini FG, D'Angelo AR, Scacchia M, Di Giannatale E, Visaggio MC, Farinelli $\mathrm{G}$, et al. Sequestro polomonare in unbufalo domestico da M. mycoides subsp. mycoides SC: isolamento, quadro anatomo-stopatologico ed immunoistochemico. Vet Ital. 1992:4:4-10.

9. OIE. Contagious bovine pleuropneumonia. 2014. http://www.oie.int/ fileadmin/Home/eng/Health_standards/tahm/2.04.09_CBPP.pdf.

10. Manso-Silvan L, Vilei EM, Sachse K, Djordjevic SP, Thiaucourt F, Frey J. Mycoplasma leachii sp. nov. as a new species designation for Mycoplasma sp. bovine group 7 of Leach, and reclassification of Mycoplasma mycoides subsp. mycoides LC as a serovar of Mycoplasma mycoides subsp. capri. IJSEM. 2009;59:1353-8.

11. Fischer A, Shapiro B, Muriuki C, Heller M, Schnee C, Bongcam-Rudloff E, et al. The origin of the 'Mycoplasma mycoides Cluster' coincides with domestication of ruminants. PLoS One. 2012;7(4):e36150.

12. Thiaucourt F, Manso-Silvan L, Salah W, Barbe V, Vacherie B, Jacob D, et al. Mycoplasma mycoides, from "mycoides Small Colony" to "capri": a microevolutionary perspective. BMC Genomics. 2011;12(1):114.

13. Thiaucourt F, Bölske G. Contagious caprine pleuropneumonia and other pulmonary mycoplasmoses of sheep and goats. Rev Sci Tech. 1996;15(4):1397-414.

14. Kusiluka LJ, Ojeniyi B, Friis NF, Kokotovic B, Ahrens P. Molecular analysis of field strains of Mycoplasma capricolum subspecies capripneumoniae and Mycoplasma mycoides subspecies mycoides, small colony type isolated from goats in Tanzania. Vet Microbiol. 2001;82:27-37.

15. Kapoor PK, Garg DN, Mahajan SK. Isolation of Mycoplasma mycoides subsp. mycoides (LC variant, Y goat) from naturally aborted bovine fetuses. Theriogenology. 1989;32:683-91.

16. Bischof DF, Janis C, Vilei EM, Bertoni G, Frey J. Cytotoxicity of Mycoplasma mycoides subsp. mycoides small colony type to bovine epithelial cells. Infect Immun. 2008;76(1):263-9.

17. Leigh SA, Wise KS. Identification and Functional Mapping of the Mycoplasma fermentans P29 Adhesin. Infect Immun. 2002;70(9):4925-35.

18. Schurwanz N, Jacobs E. Strategy to create chimeric proteins derived from functional adhesin regions of Mycoplasma pneumoniae for vaccine development. Infect Immun. 2009;77(11):5007-15.

19. Graham SP, Pellé R, Yamage M, Mwangi DM, Honda Y, Mwakubambanya RS, et al. Characterization of the fine specificity of bovine CD8 T-cell responses to defined antigens from the protozoan parasite Theileria parva. Infect Immun. 2008;76(2):685-94.

20. Thomas A, Sachse K, Farnir F, Dizier I, Mainil J, Linden A. Adherence of Mycoplasma bovis to bovine bronchial epithelial cells. Microb Pathog. 2003;34(3):141-8.

21. Ryan US. Isolation and culture of pulmonary endothelial cells. Environ Health Perspect. 1984;56:103-14.

22. Schweizer M, Peterhans E. Oxidative stress in cells infected with bovine viral diarrhoea virus: a crucial step in the induction of apoptosis. J Gen Virol. 1999;80(5):1147-55.

23. Litamoi J-K, Palya V-J, Sylla D, Rweyemamu M-M. Quality controls testing of contagious bovine pleuropneumonia live attenuated vaccine-standard operating procedures. Rome: FAO Animal Production and Health Paper 128, FAO; 1996. http://www.fao.org/docrep/003/v9952e/N9952E00.htm\#TOC.

24. FLOWJO. Version 7.6.3. 2014. http://company.flowjo.com.

25. John B, Bashiruddin JB, de Santis P, Persson A, Regalla J. Detection of Mycoplasma mycoides subspecies mycoides SC in bovine lung and lymph node tissues by culture, sandwich ELISA and polymerase chain reaction systems. Res Vet Sci. 2005;78:199-205.

26. Wesonga HL, Manso Silvan L, Thiaucourt F. Towards sustainable CBPP control programmes for Africa: CBPP vaccine strain T1 44: possible reversion to virulence. Rome: FAO Animal Production and Health Division, FAO-OIE-AU/IBAR-IAEA Consultative Group on CBPP; 2003. http://www fao.org/3/a-y5510e/y5510e0i.htm.

27. Razin S. 1992. Mycoplasma taxonomy and ecology. In: Maniloff J, McElhaney RN, Finch LR, Baseman JB, editors. Mycoplasmas: molecular biology and pathogenesis. Washington, D.C: American Society for Microbiology; 1993. p. 3-22.

\section{Submit your next manuscript to BioMed Central and take full advantage of:}

- Convenient online submission

- Thorough peer review

- No space constraints or color figure charges

- Immediate publication on acceptance

- Inclusion in PubMed, CAS, Scopus and Google Scholar

- Research which is freely available for redistribution 